\title{
Effects of Mothers' Perfectionism on Their Adolescent Daughters' Moral Disengagement Through Mothers' Psychological Control
}

\author{
Eun-Hye Sohn ${ }^{1}$, Sae-Young Han ${ }^{2}$ \\ M. A., Department of Child Development \& Intervention, Ewha Womans University, Seoul, Korea ${ }^{1}$ \\ Professor, Department of Child Development \& Intervention, Ewha Womans University, Seoul, Korea ${ }^{2}$ \\ 어머니의 완벽주의가 심리적 통제를 통해 여자 청소년의 도덕적 \\ 이탈에 미치는 영향 \\ 손은혜 ${ }^{1}$, 한세영 ${ }^{2}$ \\ 이화여자대학교 아동학과 석사 ${ }^{1}$, 이화여자대학교 아동학과 교수 ${ }^{2}$
}

Objectives: To investigate the effects of mothers' perfectionism on their adolescent daughters' moral disengagement through mothers' psychological control.

Methods: The participants were third-year female students from a girls' high-school in Incheon. The adolescents were asked to complete the questionnaires of Almost Perfectionism Scales-Revised, Psychological Control Scale-Youth Self-Report, and Mechanism of Moral Disengagement Scale. The data were analyzed by means of Pearson's correlation and Structural Equation Modeling.

Results: The results of this study are as follows. Mothers' perfectionism had an indirect influence on female adolescents' moral disengagement through mothers' psychological control. In other words, high levels of perceived mothers' perfectionism influence indirectly female adolescents' moral disengagement by an increase of perceived mothers' psychological control.

Conclusions: The findings of this study have important implications for research on female adolescents' moral disengagement. The results demonstrate that mothers' psychological attributes and parenting behaviors related to perfectionism have a decisive effect on the development of female adolescents' moral disengagement.

Keywords: perfectionism, psychological control, moral disengagement, mother-daughter relationship

\section{Introduction}

현대 사회의 청소년들은 유해한 환경의 영향으로 인해 비행, 범죄, 폭력 및 약물 남용 등과 같은 사회 문제에 관여하게 될 우려가 있다(Bronfenbrenner, 1979; Hwang, Kim, \& Kim, 2015) 청소년기에 겪는 부적응 문제가 성인기 발달에도 해로운 영향 을 미친다는 점을 고려하면, 청소년의 반사회적 행동과 관련

Corresponding Author: Sae-Young Han, Professor, Department of Child Development \& Intervention, Ewha Womans University, 52, Ewhayeodaegil, Seodaemun-gu, Seoul, Korea

E-mail: evenhow@ewha.ac.kr
한 요인들의 탐색은 매우 필요하다. 반사회적 행동을 보이는 청소년들의 특성과 관련하여 청소년폭력예방재단에서 시행 한 2011년도 폭력실태조사를 살펴보면, 가해 원인의 1순위는 ‘장난', 2순위가 '상대방의 잘못’이었으며, 가해 행동을 중지하 게 된 계기에 대해서는 1 순위가 '스스로 나쁜 행동임을 깨닫게 되어서'로 나타났다. 또한, 가해 행동을 나타내는 청소년들이 그렇지 않은 청소년들에 비해 도덕적 정서나 도덕적 책임감

(C)The Korean Association of Child Studies

This is an Open Access article distributed under the terms of the Creative Commons Attribution Non-Commercial License (http:// creativecommons.org/licenses/by-nc/4.0) which permits unrestricted noncommercial use, distribution, and reproduction in any medium, provided the original work is properly cited. 
을 더 낮게 지각하고 있다는 연구도 보고되었다(Menesini et al., 2003). 이러한 결과들은 청소년의 반사회적 행위의 기제가 해 로운 행위에 대한 정당화나 책임감의 약화와 같은 심리적 기제 에 기인한 것임을 시사한다. 선행연구들에서는 청소년의 반사 회적 행동에 대한 영향력 있는 변인으로 도덕적 이탈을 제시한 바 있다(Almeida, Correia, \& Marinho, 2009; Hymel \& Bonanno, 2014; Seo, 2013). 특히 Bandura, Barbaranelli, Caprara와 Pastorelli (1996)는 사회인지 이론을 기반으로 도덕적 이탈의 개념을 도 입하면서, 개인이 어떠한 인지적 왜곡 과정을 통해 비도덕적 행위에 연루되는지 설명하였다. 도덕적 이탈은 개인의 도덕적 기준 및 규범과 맞지 않는 비도덕적 행위가 이루어질 때 발생 하는 심리적 긴장을 줄이기 위한 자기 조절적 과정으로, 자신 이 보인 해로운 행위의 결과를 인정하기보다 자기 설득을 통해 이를 합리화하는 인지 왜곡 과정으로 정의된다(Bandura et al., 1996). 따라서 반사회적 행동과 밀접한 관련이 있는 도덕적 이 탈의 출현 요인을 확인하는 것은 청소년의 사회 문제를 예방하 고 관리하는 데 도움을 줄 것으로 기대된다.

그러나 도덕적 이탈의 선행변인을 규명하는 연구들은 아직 초기 단계에 머물러 있는 상황이다. 몇몇 선행연구들에서는 청소년의 도덕적 이탈을 환경적 요인을 통해 설명하고자 했 는데, 그중에서도 부모의 양육과 관련된 요인이 도덕적 이탈 과 밀접한 관련이 있는 선행변인으로 보고되었다(Bao, Zhang, Lai, Sun, \& Wang, 2015; Wang et al., 2017). 특히 국내에서는 부 모의 기준에 자녀가 순응하도록 통제하는 역기능적 양육 행동 인 심리적 통제가 청소년의 도덕적 이탈과 밀접한 관련이 있 음을 경험적으로 검증하였다(J. M. Kim \& Kim, 2013). 심리적 통제는 자녀를 조종하려는 부모의 심리적 필요에서 비롯되는 역기능적 양육 행동으로, 자녀가 부모의 기대대로 행동하지 않을 경우 암시적 방법을 통해 자녀를 통제하는 것으로 정의 된다(Barber \& Harmon, 2002).

부모의 심리적 통제가 청소년의 도덕적 이탈로 귀결되는 메커니즘은 자기 결정성 이론과 사회인지 이론을 통해 설명 될 수 있다. 우선, 자기 결정성 이론에서는 모든 인간이 자신의 행동을 주체적으로 이끌고자 하는 자율성의 욕구를 선천적으 로 내재하고 있다고 강조하면서, 자율성의 충족 여부가 개인 의 적응적 및 부적응적 발달 여부를 예측한다고 하였다(Deci \& Ryan, 1987). 즉, 자기 결정성 이론에서는 개인이 자율성이 라는 내적 통제요소를 지지받는 환경에 속하면 적응적 발달을 이룰 수 있지만, 강압이나 강요에 의한 외적인 통제의 영향을 받을 경우 부적응적 발달 결과에 직면할 가능성이 높을 것으 로 바라본다(Soenens \& Vansteenkiste, 2010). 그러므로 부모의
심리적 통제는 자녀의 심리적 욕구와 정서를 존중하지 않고 의사결정 및 표현을 제한하여 청소년의 자율성 발달을 저해한 다는 점에서(Barber \& Harmon, 2002), 청소년의 내재화 및 외 현화 문제와 같은 부적응적인 발달과 밀접한 관련이 있을 것 을 추론해볼 수 있다(Chon \& Sohn, 2013; El-Sheikh, Hinnant, Kelly, \& Erath, 2010).

다음으로 발달에서 모방을 중요한 수단으로 제시한 사회인 지 이론에 따르면, 청소년의 도덕적 이탈을 유발하는 잠재적 선행변인은 반사회적 행동을 모델링하는 경험이거나 적어도 그것을 용납하는 태도 혹은 신념에 노출되는 경험이어야 한 다(Bandura et al., 1996). 이러한 관점에서 부모의 심리적 통제 는 자녀에게 비난을 통해 죄책감과 수치심을 불러일으키는 환 경이므로, 심리적 통제에 지속해서 노출된 청소년들은 어떠한 문제를 다룰 때 합리적이고 온건하게 대처하기보다 비합리적 이고 자극적으로 반응하는 부모의 태도를 답습할 가능성이 있 다. 또한, 부모가 자녀를 비난한 것처럼 자녀 또한 상대방을 비 난하는 사고를 발달시킬 수 있으며, 이는 개인에게 발생하는 문제에 대하여 책임감을 함양하도록 하기보다는 그 행위의 책 임을 타인에게 돌리고, 타인을 비난하며, 자신의 행동을 정당 화하는 태도를 학습하게 한다. 따라서 이와 같은 냉혹한 양육 환경에 노출된 청소년들은 주류의 가치 및 규범으로부터 더 쉽게 도덕적으로 이탈하는 발달적 부적응을 보일 수 있다. 즉, 심리적 통제와 같이 거부적이고 냉담한 양육은 청소년과 부모 의 부정적인 상호작용을 통해서, 청소년 자녀로 하여금 도덕 적 기준을 준수하지 못하며 문제행동을 더 쉽게 수용하도록 만든다(Fontaine, Fida, Paciello, Tisak, \& Caprara, 2014; Hyde, Shaw, \& Moilanen, 2010).

종합하면, 부모의 심리적 통제는 억압과 조종을 통해 자녀 의 자율성 발달을 저해하고, 애정을 철회하거나 죄책감을 유 발하여 청소년에게 부정적 심리 상태를 경험하게 함으로써 청 소년의 도덕성 발달에 해로운 영향을 미칠 것으로 예상된다. 선행연구들을 살펴보면, 부모의 거부적인 양육 태도는 청소년 의 도덕적 이탈 수준을 증가시켰으며(Park, Kim, \& Tak, 2011), 긍정적 부모-자녀 관계의 한 측면인 부모 애착과 도덕적 이탈 은 부적 상관관계로 나타났다(Bao et al., 2015). 또한, 청소년이 부모의 심리적 통제를 높게 지각할수록 청소년의 도덕적 이 탈 수준은 증가하는 것으로 밝혀졌다(J. M. Kim \& Kim, 2013; Lee, 2016). 이러한 결과들은 부모의 부정적인 양육 행동과 청 소년의 도덕적 이탈 간의 관련성을 암시하며, 특히 부모의 심 리적 통제가 청소년의 도덕적 이탈에 미치는 해로운 영향을 보여주고 있다. 
한편, 선행연구들에서는 부모의 심리적 통제에 영향을 미 치는 개인 내적 변인에 대하여 부모의 완벽주의를 설명력 있 는 변인으로 제시하고 있다. 심리적 통제는 비판적이고 성취 지향적이며 지나치게 요구적임과 동시에 엄격한 것으로 묘 사되는데, 이는 완고한 개인적 기준을 추구하며 자신과 타인 의 평가에 비판적인 완벽주의의 특성과 밀접한 관련이 있다

(Barber \& Harmon, 2002; Frost, Marten, Lahart, \& Rosenblate, 1990). 완벽주의적인 부모들은 개인의 소망과 기대를 중요한 타인에게도 투영하며 부과하려는 경향이 있기 때문에, 부모 가 완벽을 추구할수록 자녀를 자신의 기준에 순응시키려 심리 적 통제를 보일 가능성이 크다(Hewitt \& Flett, 1990; Soenens, Vansteenkiste, Luyten, Duriez, \& Goossens, 2005). 국내의 선행 연구들에서도 어머니의 타인 지향적 완벽주의와 심리적 통제 는 남아에게서 정적인 상관을 나타냈으며(H.-Y. Kim \& Park, 2008), 완벽주의와 심리적 통제의 하위요인 간에 유의한 상관 관계가 있는 것으로 나타났다(Wang \& Han, 2013).

그러나 부모의 완벽주의와 자녀의 도덕적 이탈 간 관계에 대해서는 이를 경험적으로 검증한 연구가 매우 드물었으며, 소수의 연구에서도 높은 기준을 추구하는 개인의 완벽주의 성향이 도덕적 이탈과 유의한 관련이 없는 것으로 나타났다 (Stoeber \& Yang, 2016). 따라서 두 변인 간의 관계를 설명할 논 리적 근거가 부족한 것으로 판단하여, 본 연구에서는 어머니 의 완벽주의가 청소년의 도덕적 이탈에 미치는 직접적인 관계 를 가정하지 않았다.

위의 연구 결과들을 종합해보면, 완벽주의 성향이 있는 부 모는 자신의 높은 기준을 자녀에게도 기대하는 경향이 있기 때문에, 부모의 기대에 맞춰 자녀를 이끌기 위해 심리적 통제 를 더 많이 사용할 가능성이 있다. 그리고 이러한 부모의 심리 적 통제는 자녀의 부정적 정서와 밀접하게 연관되어 자녀의 도덕적 이탈에 영향을 미칠 것으로 예상할 수 있다. 다시 말해, 완벽주의는 완벽함이라는 도달할 수 없는 목표를 추구하는 경 향성이라는 점에서, 부모가 자녀에 대해 완벽주의를 발휘하게 될 경우 자녀는 자신이 부모의 기준을 충족시킬 수 없다는 사 실에 좌절을 경험하게 된다. 이러한 과정에서 자녀는 본인의 결함에 대해 떳떳하지 못하여 이를 감추고 변명하려는 방어적 인 태도를 형성할 수 있다. 특히 청소년기는 부모로부터 높은 성취 압력을 받을 수 있는 시기이기 때문에 부모의 자녀에 대 한 완벽주의로 인해 파생하는 부정적인 발달적 결과가 더욱 클 것으로 판단된다. 선행연구의 결과들은 청소년의 도덕적 이탈을 감소시키기 위하여, 부모의 내면과 관련한 위험요인들 을 확인하고 중재하는 것이 매우 중요한 작업임을 시사한다.
그럼에도 불구하고 기존의 연구들에서는 도덕적 이탈을 설 명하는 변인으로 부모 양육 요인만을 탐색하거나 청소년의 개인 내적 요인에 대해 탐색한 바는 있었으나(Bao et al., 2015; Wang et al., 2017; Yun, 2017), 도덕적 이탈을 유도하는 부모의 양육 행동과 그 양육의 배경이 되는 부모의 심리 상태까지 관 심을 둔 경우는 드물었다. 또한, 청소년의 도덕적 이탈에 영향 을 미치는 부모의 양육 행동과 내면 요인에 대해 부와 모의 독 립적인 영향을 살펴본 연구도 많지 않았다. 더불어, 완벽주의 적 성향을 가진 부모가 자녀에게 심리적 통제를 취함에 있어 서도 어머니와 남아, 아버지와 여아 간의 관계를 밝힌 연구는 있었으나(H.-Y. Kim \& Park, 2008; Soenens et al, 2013), 동성 부 모의 영향을 살펴본 연구는 다소 제한적이었다. 최근 현대 사 회는 부 위주의 가부장적인 기존 체계에서 벗어나 부모가 동 등하거나 혹은 모가 중심이 되는 가족체계로 변화해가는 양상 을 보이고 있다(Im \& Chun, 2009). 이러한 변화는 모와 자녀 간에 이전보다 더 긴밀한 관계가 조성되게 하고 있으며, 특히 가족 내 여러 하위 체계 중에서도 모녀 관계는 더욱 강도 높고 지속적인 체계로 이해되고 있다(Nam \& Han, 2002). 그러므로 청소년의 도덕적 이탈과 부모의 성격 특성 및 양육 행동 간의 관계에서 모녀 관계의 역학을 탐색하는 것은 의미 있는 연구 가 될 것이다.

이러한 연구의 필요성에 따라, 본 연구는 어머니의 완벽주 의가 심리적 통제를 통해 여자 청소년의 도덕적 이탈에 미치 는 간접적인 영향력을 검증하는 것을 목적으로 하였다. 본 연 구를 통해 위 가정이 확인된다면, 여자 청소년의 도덕적 이탈 과 어머니 관련 위험 요인 간의 관계를 더욱 명확히 이해할 수 있을 것이며, 청소년 상담과 부모교육 프로그램 등에 필요한 이론적 기초자료를 제공할 수 있을 것이다. 이를 위해 본 연구 에서 설정한 연구 문제는 다음과 같다(Figure 1).

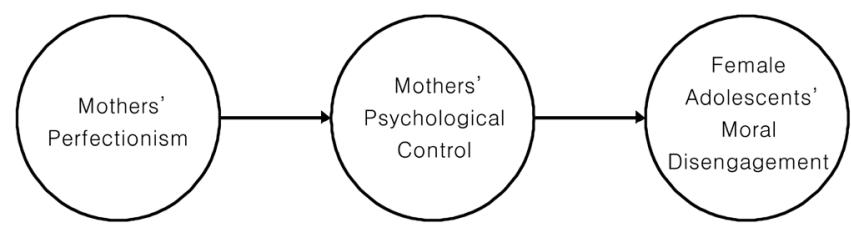

Figure 1. Pathways from mothers' perfectionism to female adolescents' moral disengagement through mothers' psychological control.

\section{연구 문제 1}

어머니의 완벽주의는 심리적 통제를 통해 여자 청소년의 도 덕적 이탈에 간접적으로 영향을 미치는가? 


\section{Methods}

\section{연구대상}

본 연구는 인천광역시 소재의 1 개 고등학교에 재학 중인 3학 년 여학생 419 명들을 대상으로 하였다. 연구 대상의 선정은 청소년기 후반기에 고차원적 인지 기능의 발달이 완성되면서 고등학생들에게서 도덕적 이탈 기제의 사용이 두드러진다는 연구결과들(J. M. Kim \& Kim, 2013; Park et al., 2011)에 기반 을 두었다. 연구 대상자의 인구통계학적 특성을 살펴보면, 여 자 고등학생들의 학년은 모두 3학년이었으며 평균연령은 만 17 세로 나타났다. 어머니의 교육 수준은 고등학교 졸업이 198 명(47.3\%)으로 가장 많았으며, 그다음으로 4년제 대학교 졸업 이 131 명(31.3\%)이었다.

\section{연구 도구}

본 연구의 질문지는 어머니의 완벽주의, 심리적 통제 및 여자 청소년의 도덕적 이탈을 측정하는 문항들로 구성되어 있으며, 질문지의 모든 응답은 청소년의 보고로 이루어졌다.

\section{완벽주의}

어머니의 완벽주의를 측정하기 위해 Slaney와 Ashby (1996) 가 개발한 '완벽성향 척도(Almost Perfectionism Scales-Revised [APS-R])'를 S. Kim (2005)이 번안하고, Jang (2011)이 자녀보고 식으로 수정한 질문지를 사용하였다. 본 척도는 높은 기준과 격차의 두 하위요인으로 이루어져 있으나, '격차'의 문항이 어 머니의 완벽주의로 인해 자녀가 경험하는 심리적 고통을 측정 하는 내용으로 구성되어 있기 때문에, 어머니의 완벽주의를 연 구하고자 하는 본 논문의 목적에는 적합하지 않은 것으로 판 단하였다. 따라서 어머니가 자녀 양육에서 완벽주의를 추구하 는 성향을 측정하기 위해 완벽성향 척도의 하위요인 중 '높은 기준'의 7문항만을 선택하여 사용하였다. "어머니는 나의 학업 이나 일에 대한 성취 기준이 높으시다."와 "어머니는 내가 다른 아이들보다 뛰어났으면 하는 바람이 강하신 것 같다.” 등의 문 항으로 구성되어 있다. 각 문항은 전혀 그렇지 않다(1점), 별로 그렇지 않다(2점), 보통이다(3점), 약간 그렇다(4점), 매우 그렇 다(5점) 의 5점 Likert식 척도를 통하여 평가되었다. 점수가 높 을수록 자녀가 지각한 어머니의 완벽주의 수준이 높음을 의미 한다. 문항 간 내적 합치도(Cronbach's $\alpha$ )는 .94 이었다.

\section{심리적 통제}

어머니의 심리적 통제는 Barber (1996)가 개발한 '심리적 통제 척도(Psychological Control Scale-Youth Self-Report [PCS-YSR])' 를 Choi (2010)가 번안한 질문지를 사용하여 측정하였다. 본 척도는 6 개의 하위요인의 16 문항으로 이루어져 있으며, 각 하 위요인별 문항의 예를 살펴보면, 자기표현 제한은 "나의 어머 니는 내가 말하는 것을 자주 방해하신다.” 등으로, 감정 불인 정은 "나의 어머니는 항상 어떤 일에 대한 나의 감정이나 생각 을 바꾸려고 하신다." 등으로 구성되어있다. 비난은 "나의 어 머니는 가족의 문제를 내 탓으로 돌리신다.” 등의 문항으로 이 루어져 있으며, 죄책감 유발은 "나의 어머니는 내가 어머니를 정말 생각한다면 걱정시킬 행동은 하지 말아야 한다고 말씀 하신다." 등의 문항으로 구성된다. 애정 철회에는 "나의 어머 니는 내가 어머니 뜻대로 하지 않으면 나를 차갑게 대하신다." 등의 문항이 포함되며, 불안정한 감정 기복은 "나의 어머니는 내게 잘 해주시다가도 비난하시는 등 나를 대하시는 방식이 자주 달라지신다.” 등으로 구성된다. 각 문항은 전혀 그렇지 않다(1점), 별로 그렇지 않다(2점), 보통이다(3점), 약간 그렇다 (4점), 매우 그렇다(5점) 의 5점 Likert식 척도를 통하여 평가되 었다. 각 하위 요인 별 문항 간 내적 합치도(Cronbach's $\alpha$ )는 자 기표현 제한이 .91, 감정 불인정이 .76, 비난이 .65, 죄책감유발 이 .64, 애정 철회가.76, 불안정한 감정기복이 .61이었다.

\section{도덕적 이탈}

여자 청소년의 도덕적 이탈을 측정하기 위해 Bandura (1996) 등이 개발한 도덕적 이탈 기제 척도(Mechanism of Moral Disengagement Scale [MMDS])를 Seo와 Kim (2006)이 번안하 고 수정한 질문지를 사용하였다. 본 척도는 8 개의 하위요인의 29문항으로 이루어져 있으며, 각 하위요인별 문항의 예를 살 펴보면, 도덕적 정당화는 “친구를 보호하기 위해 싸움하는 것 은 관찮다." 등으로, 완곡한 명명은 “다른 아이를 밀치거나 떠 미는 것은 일종의 장난이다.” 등으로 구성되어 있다. 유리한 비교는 "심각한 불법 행동에 비하면, 가게에서 물건을 훔치는 것은 그리 나쁜 일이 아니다." 등의 문항으로, 책임 전가는 "친 구가 강제로 시켜서 나쁜 행동을 한 아이를 탓할 수 없다.” 등 의 문항으로 구성된다. 책임 분산은 "여럿이서 나쁜 행동을 하 자고 결정했다면 집단 내 한 아이만 나쁘다고 하는 것은 불공 평하다." 등의 문항으로, 결과 왜곡은 “다른 사람에게 해가 되 지 않으면 사소한 거짓말은 해도 괜찮다.” 등의 문항으로 이루 
어져 있다. 피해자의 비인간화는 "부드럽게 대해서 안 통하는 사람들은 거칠게 다루어야 한다.” 등의 문항으로, 비난에 대 한 귀인은 "또래에게 괴롭힘을 당하는 아이들은 대개 그럴만 한 행동을 한다.” 등으로 구성된다. 각 문항은 전혀 그렇지 않 다(1점), 별로 그렇지 않다(2점), 보통이다(3점), 약간 그렇다 (4점), 매우 그렇다(5점) 의 5점 Likert식 척도를 통하여 평가되 었다. 각 하위 요인 별 문항 간 내적 합치도(Cronbach's $\alpha$ )는 도 덕적 정당화가 .67 , 완곡한 명명이 .57 , 유리한비교가 .83 , 책임 전가가 .76, 책임 분산이 .92, 결과 왜곡이 .60, 비인간화가.73, 비난의 귀인이 .40 이었다. 완곡한 명명과 비난에 대한 귀인의 신뢰도는 각각 $.40, .57$ 이하로 다소 낮았다. 이는 Lee (2016)와 Yun (2017)의 연구 결과와 유사한 것으로, 해당 연구들에서도 두 하위요인에 대한 내적 일치도가 낮게 나타나 문항 묶음 방 법을 사용하거나 하위요인을 제거한 후 분석하였다. 완곡한 명명과 비난의 귀인이 국내연구에서 일관적으로 낮은 신뢰도 를 보이는 것은 개인의 책임 소재에 대한 인식과 표현이 문화 적으로 차이를 갖기 때문으로 추론해볼 수 있다. 이에 국내 문 화에 문제없이 적용 가능한 하위 요인들을 중심으로 분석하기 위해 완곡한 명명과 비난의 귀인을 제거한 후 사용하였다.

\section{연구 절차}

본 연구의 자료 수집은 2018년 2월 인천시 소재의 한 여자 고 등학교에 재학 중인 청소년들을 대상으로 이루어졌다. 설문 을 시행하기 전, 연구자가 각 학급의 담임교사와 임원에게 연 구에 대해 소개하였고 설문지의 목적 및 응답 시 유의사항에 관해 설명하였다. 각 학급의 임원들이 학생들에게 설문지를 배부한 후 여자 청소년들이 자기보고식으로 응답한 설문지를 회수하였다. 모든 설문지는 배부 후 당일 회수하였으며, 배부 된 450 부 중 419 부가 회수되어 약 $93.1 \%$ 의 회수율을 보였다. 그 결과 모든 변인의 왜도와 첨도의 절댓값이 각각 3 과 10 미 만으로 나타나(G. Kim, 2010) 정규성이 확보되어 최종 분석에 419부를 사용하였다.

\section{자료 분석}

본 연구의 자료는 SPSS 21.0 (IBM Co., Armonk, NY)프로그램 과 AMOS 21.0 (IBM Co., Armonk, NY)프로그램을 이용하여 다음의 방법을 통해 분석하였다. 먼저 연구대상의 인구통계 학적 배경 및 각 변인 간의 일반적 경향을 살펴보기 위해 평균 과 표준편차를 산출하였다. 측정 도구의 문항 간 내적 합치도
를 알아보기 위해 Cronbach's $\alpha$ 값을 구하였으며, 각 변인 간의 상관관계를 알아보고자 Pearson의 적률상관계수를 산출하였 다. 마지막으로 어머니의 완벽주의가 심리적 통제를 통해 여 자 청소년의 도덕적 이탈에 미치는 간접적인 영향력을 알아보 기 위해 구조방정식 모형(structural equation modeling)을 분석 하였고, 간접 효과의 유의성을 평가하기 위해 부트스트래핑 (bootstrapping) 방법을 이용하여 검증하였다.

\section{Results}

\section{측정 변인들 간 상관관계}

본 연구의 주요변인인 어머니의 완벽주의, 심리적 통제 및 여자 청소년의 도덕적 이탈 간의 관계를 살펴보기 위하여 Pearson의 적률상관계수를 산출하였다(Table 1). 그 결과를 구 체적으로 살펴보면 다음과 같다. 첫째, 어머니의 완벽주의는 심리적 통제의 모든 하위요인과 유의한 정적 상관을 보였다 $(r=.25 \sim .39, p<.01)$. 둘째, 어머니의 완벽주의는 여자 청소년 의 도덕적 이탈의 하위요인 중 도덕적 정당화 $(r=.20, p<.01)$ 및 비인간화 $(r=.15, p<.01)$ 와 유의한 정적 상관을 나타냈다. 셋째, 어머니의 심리적 통제와 여자 청소년의 도덕적 이탈 간 의 관계를 살펴보면, 먼저 심리적 통제의 하위요인 중 자기표 현 제한은 도덕적 이탈의 하위요인 중 유리한 비교 $(r=.20, p<$ $.01)$, 결과 왜곡 $(r=.21, p<.01)$ 및 비인간화 $(r=.17, p<.01)$ 와 통계적으로 유의한 정적 상관을 보였다. 다음으로 심리적 통 제의 하위요인 중 감정 불인정은 도덕적 이탈의 하위요인 중 도덕적 정당화 $(r=.17, p<.01)$ 및 비인간화 $(r=.12, p<.05)$ 와 정적 상관을 나타냈다. 심리적 통제의 하위요인 중 비난, 죄책 감 유발, 애정 철회 및 불안정한 감정 기복은 도덕적 이탈의 모 든 하위요인과 통계적으로 유의한 정적 상관을 나타냈다 $(r=$ $.10 \sim .27, p<.05 \sim .01)$. 한편, 도덕적 이탈의 하위 요인 중 책임 분산은 다른 모든 하위 요인들과 일관적으로 부적 상관을 나 타냈다. 따라서 책임 분산은 도덕적 이탈의 타 하위요인들과 는 다른 의미를 측정하고 있는 것으로 파악되어 최종 분석에 서는 이를 제외하였다.

\section{항목 묶음}

본 연구는 어머니의 완벽주의를 측정하기 위해 완벽성향척도 (APS-R)의 하위요인 가운데, 높은 기준 요인의 7 문항을 선택 
Table 1

Correlations Among Perfectionism, Psychological Control, and Moral Disengagement

\begin{tabular}{|c|c|c|c|c|c|c|c|c|c|c|c|c|}
\hline Variables & 1 & 2 & 3 & 4 & 5 & 6 & 7 & 8 & 9 & 10 & 11 & 12 \\
\hline \multicolumn{13}{|l|}{ Perfectionism } \\
\hline 1. High standards & - & & & & & & & & & & & \\
\hline \multicolumn{13}{|l|}{ Psychological control } \\
\hline 2. Constrain verbal expressions & $.25^{* *}$ & - & & & & & & & & & & \\
\hline 3. Invalidating feelings & $.37^{* *}$ & $.47^{* *}$ & - & & & & & & & & & \\
\hline 4. Personal attacks & $.28^{* *}$ & $.54^{* *}$ & $.51^{* *}$ & - & & & & & & & & \\
\hline 5. Guilt induction & $.39^{* *}$ & $.44^{* *}$ & $.53^{* *}$ & $.61^{* *}$ & - & & & & & & & \\
\hline 6. Love withdrawal & $.30^{* *}$ & $.52^{* *}$ & $.43^{* *}$ & $.61^{* *}$ & $.53^{* *}$ & - & & & & & & \\
\hline 7. Erratic emotional behavior & $.31^{* *}$ & $.55^{* *}$ & $.49^{* *}$ & $.68^{* *}$ & $.58^{* *}$ & $.68^{* *}$ & - & & & & & \\
\hline \multicolumn{13}{|l|}{ Moral disengagement } \\
\hline 8. Moral justification & $.20^{* *}$ & .08 & $.17^{* *}$ & $.20^{* *}$ & $.21^{* *}$ & $.14^{* *}$ & $.18^{* *}$ & - & & & & \\
\hline 9. Advantageous comparisons & .05 & $.20^{* *}$ & .06 & $.17^{* *}$ & $.10^{*}$ & $.25^{* *}$ & $.21^{* *}$ & $.12^{*}$ & - & & & \\
\hline 10. Displacement of responsibility & .05 & .07 & .06 & $.12^{*}$ & $.17^{* *}$ & $.22^{* *}$ & $.15^{* *}$ & $.22^{* *}$ & $.24^{* *}$ & - & & \\
\hline 11. Distortion of consequences & .09 & $.21^{* *}$ & .09 & $.13^{* *}$ & $.15^{* *}$ & $.15^{* *}$ & $.18^{* *}$ & $.28^{* *}$ & $.31^{* *}$ & $.27^{* *}$ & - & \\
\hline 12. Dehumanization & $.15^{* *}$ & $.17^{* *}$ & $.12^{*}$ & $.24^{* *}$ & $.27^{* *}$ & $.24^{* *}$ & $.26^{* *}$ & $.36^{* *}$ & $.10^{*}$ & $.19^{* *}$ & $.31^{* *}$ & - \\
\hline
\end{tabular}

Note. $N=419$.

${ }^{*} p<.05 .{ }^{* *} p<.01$.

하여 사용하였다. 그러나 구조방정식 모형은 잠재변수당 문항 수가 많을수록 추정 오차가 커질 수 있으므로(Kline, 2010), 구 조방정식 모형 분석의 실행을 위하여 각각의 문항들을 부분적 으로 합산하여 측정변수로 설정하는 항목 묶음(item parceling) 방법을 사용하였다(Little, Cunningham, Shahar, \& Widaman, 2002). 본 연구에서 어머니의 완벽주의는 단일 차원으로 구성 되어 있으므로 Kishton과 Widaman (1994)의 제안에 따라 7개 의 문항을 2 개의 항목에 순서대로 할당하였다.

\section{측정모형 분석}

본 연구 모형의 구조적 관계 분석 전, 어머니의 완벽주의, 심리 적 통제 및 여자 청소년의 도덕적 이탈을 측정하는 하위 요인 들이 잠재변인을 잘 측정하고 있는지 확인하기 위해 확인적 요인분석(confirmatory factor analysis)을 하였다. 확인적 요인분 석의 모수 추정은 최대우도법(maximum likelihood estimation) 을 사용하였다. 측정 모형의 적합도는 $\chi^{2}$ 와 $\chi^{2} / d f$, Tucker-Lewis Index (TLI), Normed Fit Index (NFI), Comparative Fit Index (CFI), Root Mean Square Error of Approximation (RMSEA)의 적 합도 지수를 살펴보았다. 적합도 평가의 기준을 보면 $\chi^{2}$ 값이 통계적으로 유의하지 않고, $\chi^{2} / d f$ 가 3 보다 작을 때 적합하다 고 판단될 수 있으나, $\chi^{2}$ 값은 표본의 크기에 따라 크게 영향을
받는다는 점을 고려해 다른 적합도 지수와 함께 모형의 적합 도를 평가한다(Hong, 2000). 이외의 적합도 지수로 NFI, TLI, $\mathrm{CFI}$ 의 값은 .90 이상일 때 적합하다고 할 수 있으며, RMSEA의 값은 .05 이하일 때 적절하고 .08 이하일 경우 양호하다고 판단 된다(G. Kim, 2010).

본 연구의 모형은 어머니의 완벽주의, 심리적 통제, 여자 청 소년의 도덕적 이탈의 세 잠재변인을 포함하고 있다. 완벽주의 는 높은 기준의 측정 변인으로 이루어져 있고, 심리적 통제는 감정 불인정, 자기표현 제한, 비난, 애정 철회, 죄책감 유발, 불안 정한 감정 기복의 여섯 가지 측정 변인으로, 도덕적 이탈은 도 덕적 정당화, 유리한 비교, 책임 전가, 결과 왜곡, 비인간화의 다 섯 가지 측정 변인으로 구성되어있다. 모형을 살펴본 결과, 측 정 모형의 적합도는 $\chi^{2}=160.86(d f=62, p<.001), \chi^{2} / d f=2.65$, $\mathrm{NFI}=.92, \mathrm{TLI}=.93, \mathrm{CFI}=.95, \mathrm{RMSEA}=.06[90 \% \mathrm{CI}=.05, .07]$ 으로 나타나 적합도 기준을 모두 충족하였다(Table 2).

본 측정모형의 요인 부하량을 살펴보면, 모든 잠재변인으 로부터 측정 변인으로의 표준화 회귀계수( $\beta$ )가 .38 .94로 나 타났다. 또한, 측정 변인들의 Critical Ratio (C.R.) 모든 값이 $\alpha$ $=.001$ 수준에서 유의해 측정 변인이 잠재변인을 적절하게 설 명하는 것으로 나타났다(Table 3, Figure 2). 
Table 2

Testing the Fit of the Measurement Model

\begin{tabular}{ccccccc}
\hline$\chi^{2}$ & $d f$ & $\chi^{2} d f$ & NFI & TLI & CFI & RMSEA \\
& (Lo90 $\sim$ Hi90) \\
\hline $160.86^{* * *}$ & 62 & 2.59 & .92 & .93 & .95 & .06 \\
\end{tabular}

Note. $N=419$.

*** $p<.001$.

Table 3

Path Estimates in the Structural Model

\begin{tabular}{lllll}
\hline \multicolumn{1}{c}{ Path loadings } & $B$ & $\beta$ & $S E$ & C.R. \\
\hline Perfectionism $\rightarrow$ Psychological control & .49 & .45 & .07 & $7.22^{* * *}$ \\
Psychological control $\rightarrow$ Moral disengagement & .19 & .46 & .03 & $5.90^{* * *}$ \\
\hline
\end{tabular}

Note. $N=419$.

${ }^{* * *} p<.001$.



Figure 2. Factor loadings of the measurement model. ${ }^{* * *} p<.001$.

\section{구조 모형 분석}

어머니의 완벽주의가 심리적 통제를 통하여 청소년의 도덕적 이탈에 영향을 미치는 간접적 경로를 확인하기 위하여 구조방 정식을 이용하여 분석하였다. 간접 경로의 유의성은 부트스트 래핑 방법을 사용하여 분석하였다. 구조 모형의 적합도 지수 는 $\chi^{2}=161.36(d f=63, p<.001), \chi^{2} / d f=2.65, \mathrm{NFI}=.92, \mathrm{TLI}=$ $.94, \mathrm{CFI}=.95, \mathrm{RMSEA}=.06[90 \% \mathrm{CI}=.05, .07]$ 로 나타나 적합 도 기준을 모두 충족하였다. 어머니의 완벽주의가 심리적 통 제를 통하여 청소년의 도덕적 이탈에 미치는 경로는 다음과 같다(Table 3). 먼저, 어머니의 완벽주의가 심리적 통제에 미치 는 직접적인 경로가 정적으로 유의하였으며 $(\beta=.45, p<.001)$, 심리적 통제가 청소년의 도덕적 이탈에 미치는 직접적인 경로 도 정적으로 유의하였다 $(\beta=.46, p<.001)$. 이를 통해 어머니 의 완벽주의가 심리적 통제를 통해 여자 청소년의 도덕적 이 탈에 미치는 간접적인 영향을 확인하였다. 어머니의 완벽주의 가 심리적 통제를 통하여 여자 청소년의 도덕적 이탈에 미치 는 모형의 검증 결과를 Figure 3에 제시하였다.

이어서, 잠재변인 간의 구조적인 관계를 구체적으로 확인 해 보고자 어머니의 완벽주의가 심리적 통제를 통해 여자 청 소년의 도덕적 이탈에 영향을 미치는 직접효과와 간접효과 및 총 효과를 살펴보았다(Table 4). 부트스트래핑 방법을 이용 하여 간접효과의 유의성을 살펴본 결과, 어머니의 완벽주의 가 심리적 통제를 통해 여자 청소년의 도덕적 이탈에 미치는 간접효과는 유의하였다 $(\beta=.20, p<.01)$ 또한, 다중상관자승 (squared multiple correlation)을 살펴본 결과, 어머니의 완벽주 




Figure 3. Direct and indirect paths from mothers' perfectionism to female adolescents' moral disengagement through mothers' psychological control.

${ }^{* * *} p<.001$.

Table 4

Direct, Indirect, and Total Effects in the Structural Equation Model

\begin{tabular}{lcccc}
\hline & \multicolumn{3}{c}{ Bootstrapping } & SMC \\
\cline { 2 - 4 } & Direct effect & Indirect effect & Total effect & $.45^{* *}$ \\
Perfectionism $\rightarrow$ Psychological control & $.45^{* *}$ & - & .20 \\
Psychological control $\rightarrow$ Moral disengagement & $.46^{* *}$ & - & $.46^{* *}$ & .21 \\
Perfectionism $\rightarrow$ Moral disengagement & - & $.20^{* *}$ & $.20^{* *}$ & .21 \\
\hline
\end{tabular}

Note. $N=419$.

${ }^{* *} p<.01$.

의는 심리적 통제를 $20 \%$ 설명하였으며, 어머니의 완벽주의와 심리적 통제는 함께 여자 청소년의 도덕적 이탈을 $21 \%$ 설명 하는 것으로 나타났다.

\section{Discussion}

본 연구는 여자 청소년들을 대상으로 어머니의 완벽주의가 심 리적 통제를 통해 여자 청소년의 도덕적 이탈에 미치는 간접 적인 영향을 살펴보았다. 본 연구를 통해 얻은 주요 결과를 요 약하고 논의하면 다음과 같다.

먼저, 어머니의 완벽주의는 심리적 통제에 직접적인 영향 을 미쳤다. 즉, 여자 청소년이 어머니가 자신에게 완벽을 요 구한다고 느낄수록, 어머니로부터 더 높은 수준의 심리적 통 제를 받는다고 지각하였음을 의미한다. 이러한 결과는 부모 가 완벽주의적 성향이 높을수록 자녀를 양육할 때 심리적 통
제를 사용하기 쉽다는 선행연구들과 맥락을 함께 한다(H.-Y. Kim \& Park, 2008; Soenens et al., 2013; Soenens, Vansteenkiste, Duriez, \& Goossens, 2006). 결과적으로 완벽주의 성향이 있는 개인이 어머니 역할을 수행할 경우, 자신의 딸에게도 완고한 기준을 부여하고 높은 성취를 요구하며, 나아가 자녀가 부모 의 기대대로 행동하게 하려고 심리적 통제를 보일 가능성이 높아지는 것으로 해석할 수 있다.

다음으로, 어머니의 심리적 통제는 여자 청소년의 도덕적 이탈에 직접적인 영향을 미쳤다. 즉, 여자 청소년이 어머니의 심리적 통제 수준을 높게 지각할수록, 도덕적 이탈이 증가하 는 결과를 보였다. 이는 부모가 자녀에게 온정적이고 자율성 을 지지하는 태도를 보일수록 자녀의 도덕성 발달이 증진되는 반면에, 강압적이고 통제적인 양육 행동을 나타낼수록 자녀의 도덕성 발달은 저해된다는 것을 밝힌 선행연구들을 지지하는 결과이다(Bao et al., 2015; Cho, 2012; Yun, 2017). 그뿐만 아니 라, 청소년이 부모의 심리적 통제를 높게 지각할수록, 도덕적 
인지 영역에서의 왜곡인 도덕적 이탈 수준이 더 높아진다는 국내 선행연구의 결과들(J. M. Kim \& Kim, 2013; Lee, 2016)과 도 유사하였다. 이는 자율성의 충족 여부가 개인의 발달과 깊 은 관련이 있음을 주장한 자기 결정성 이론(self-determination theory)의 관점과 일치하며, 개인을 둘러싼 환경적인 요인들 이 도덕성 발달에 미치는 영향에 대해 설명한 사회인지 이론 (social cognitive theory)과도 맥락을 함께하는 바이다. 특히, Wang 등(2017)은 사회인지 이론의 관점에서 이와 같은 현상 을 설명하였는데, 청소년이 부모의 심리적 통제와 같은 부정 적인 양육에 반복적으로 노출될 경우 타인에게 벌어지는 해로 운 상황에 대해 인지적으로 둔감화 될 수 있다고 하였다. 인지 적 둔감화는 타인에게 부정적 영향력을 끼치는 행위에 대해 다소 완화된 도덕적 평가를 하도록 이끌어 결국 그 행위에 대 한 정당화를 가속하게 된다. 또한, 부모의 심리적 통제는 자녀 의 자기표현을 제한하거나 감정을 인정하지 않고, 부모의 심 리상태에 따라 자녀에게 조건적으로 애정을 부여하거나 철회 함으로써 자녀가 수치심과 죄책감을 경험하도록 하는 양육 행 동으로 이해된다. 이러한 부모-자녀 간 역동이 발생하는 동안 부모는 자녀를 비난하는 태도를 보이기 쉬운데, 이때 청소년 자녀가 부모의 비판을 건전하게 수용하기보다 오히려 이런 상 황만을 모면하고자 자신의 결함을 감추고 변명하는 사고를 발 달시키게 되는 것으로 추론할 수 있다.

마지막으로, 어머니의 완벽주의가 심리적 통제를 통해 여 자 청소년의 도덕적 이탈에 미치는 간접 경로는 유의하였다. 이는 어머니가 자녀에게 완벽함을 요구한다고 여자 청소년이 지각할수록 어머니의 심리적 통제도 크게 지각하며, 결과적 으로 도덕적 이탈 수준이 높아진다는 것을 의미한다. 이와 같 은 결과는 부모의 심리적 특성이 양육 행동에 직접적인 영향 을 미치고, 이는 다시 자녀의 발달에 간접적인 영향을 미친다 고 설명한 Belsky (1984)의 양육결정요인과정 모델을 지지한 다. 완벽주의를 추구하는 어머니는 자녀가 자신의 엄격한 기 준을 충족하여 높은 성과를 이뤄내길 원하기 때문에 자녀 양 육 시 심리적 통제를 사용하여 자녀를 조종하려 하기 쉽다. 이 러한 과정에서 자녀는 부모의 비난을 피하고자 자신의 결함이 나 실수를 정당화하는 교묘한 심리적 기제를 발달시킬 가능성 이 있는 것으로 해석된다. 이는 자녀에 대한 어머니의 완벽주 의가 자녀 양육 시 성취 지향과 같은 좋은 의도로 발휘될지라 도, 오히려 자녀에게 지나친 기대에 대한 심리적 부담감을 가 지게 하여 책임을 회피하거나 타인을 비난하는 도덕적 이탈과 같은 부정적인 발달에 직면하게 한다는 점에서 모순되는 결과 라 할 수 있다.
특히 본 연구에서는 이와 같은 결과를 모녀 관계에서 확인 했다는 점에서 기존의 선행연구 결과와 차별화되는 의미를 찾 을 수 있다. 기존의 부모 양육과 청소년의 도덕적 이탈에 관한 선행연구들에서는 청소년의 도덕적 이탈에 대하여 이성 부모 의 영향력을 증명하였다. Yun (2017)의 연구에서는 이성 부모 의 온정적인 양육이 각각 남자 청소년과 여자 청소년의 도덕 적 이탈에 영향을 미쳤으며, Trentacosta 등(2011)은 모-자 간 온 정 수준이 남자 청소년의 도덕적 이탈 수준을 낮춘다는 연구 결과를 보고하였다. 본 연구에서는 동성 부모인 어머니가 가 진 내적 요인과 양육요인이 동성 자녀인 딸의 도덕적 이탈에 미치는 영향을 탐색한 결과, 높은 기준을 가진 어머니가 자녀 를 양육할 때 동성의 자녀인 딸을 자신과 동일시하여 본인의 기대와 소망을 딸에게 강하게 투영하여 심리적으로 통제하려 는 경향을 보였고, 이로 인해 딸의 도덕성 발달에 부정적인 영 향을 미친 것으로 추론해볼 수 있다. 이성 부모의 온정적 양육 과 이성 자녀의 도덕적 이탈의 관계를 밝힌 선행연구의 결과 와 비교해볼 때, 본 연구 결과는 동성 부모이기 때문에 가능한 동일시 과정의 부정적인 효과에 대해 시사점을 제공한다고 볼 수 있다. 즉, 자녀의 도덕적 이탈의 발달에 있어, 이성 부모인 경우 온정적 양육 태도와 같은 일반적 양육 태도의 영향을 고 려해야 하나, 동성 부모인 경우 자녀와 동일시함으로써 자녀 에게 투영할 수 있는 동성 부모 자신의 내적 요인이 중요한 영 향력을 가진다는 점을 암시하는 것이다.

또한, 본 연구의 특기할 만한 사항은 도덕적 이탈 기제 척도 의 하위요인 중 ‘책임 분산’이 다른 하위요인들과 반하는 경향 을 보여, 타 요인들과는 다른 의미를 측정하고 있는 것으로 파 악되었다는 점이다. 책임 분산의 문항 내용을 살펴보면, "다른 아이들도 잘못했다면, 그러한 잘못을 먼저 하자고 제안한 아 이만 혼내서는 안 된다.", "집단이 한 나쁜 행동에 대해 한 아 이에게만 책임을 지우는 것은 불공평하다.” 등으로 구성되어 있다. Bandura 등(1996)에 의하면, 책임 분산의 기제는 집단에 서 발생한 유해한 행위에 대한 책임을 세분화하여 죄책감을 덜어내는 것으로 설명된다. 그러나 흥미롭게도 본 연구의 대 상자들은 책임감을 분산시키기보다, 오히려 집단의 해로운 행 위에 관한 책임을 구성원들과 함께 짐으로써, 비도덕적인 행 위에 대한 죄책감을 덜어내어 심리적 안전감을 확보하려는 경 향을 나타냈다. 이와 같은 결과는 집단 책임 의식에 대한 문화 적 인식의 차이에서 기인한 것으로 추론해볼 수 있다. 즉, 개인 주의적 사상이 발달한 서양에 비해 한국의 문화는 상대적으로 집단 내에서의 책임감과 연대 의식 등을 중요한 덕목으로 생 각하는 경향이 있기 때문에, 이러한 문화적 배경의 차이가 본 
연구의 결과를 설명하는 것으로 보인다. 그러므로 연구 대상 자들이 속한 문화에 따라 달라지는 집단적 책임의식의 지각이 책임 분산을 측정하는 데 있어 어떠한 영향을 미치는가에 관 하여 추가적인 비교 문화 연구가 수행될 필요가 있겠다.

본 연구의 제한점 및 후속연구를 위한 제언은 다음과 같다. 첫째, 본 연구는 인천시 소재의 1 개 여자 고등학교에서 3 학년 학생들을 대상으로 하였으므로, 연구 결과의 해석을 전체 여 자 청소년으로 확대하는 데 있어서 제한이 따를 수 있다. 따라 서 후속연구에서는 지역과 연령에 수반하는 차이점을 고려하 여 적절한 표집 방법을 사용함으로써, 본 연구 결과의 일반화 가능성을 확인할 필요가 있다. 둘째, 본 연구는 모든 변인을 청 소년의 자기보고식 질문지를 통해 측정하였기 때문에 공유 분 산(shared variance)의 문제점이 제기된다. 따라서 후속연구에 서는 어머니 관련 변인을 어머니에게서 직접 측정하여 연구의 객관성을 확보할 필요가 있을 것이다. 셋째, 본 연구에서 도덕 적 이탈의 하위요인 중 ‘완곡한 명명'과 ‘비난의 귀인'에 대한 내적 일치도가 다른 하위요인들에 비해 다소 낮게 나타난 바 있다. 이는 Lee (2016)와 Yun (2017)의 연구 결과와 유사한 것 으로, 해당 연구들에서도 두 하위요인에 대한 내적 일치도가 낮은 것으로 확인되었다. 따라서 후속 연구에는 본 연구를 통 해 확인된 국내 도덕적 이탈 기제 척도의 한계점들을 보완하 기 위한 타당화 작업이 필요할 것이다.

위와 같은 제한점이 있음에도 불구하고, 본 연구는 다음과 같은 의의를 가진다. 첫째, 청소년기는 고차원적인 인지기능 이 발달하여 추상적 사고 및 가설적 사고가 증가하는 단계로, 청소년들은 이 시기에 이르러 비로소 도덕적 책임 의식이라는 추상적인 개념을 확립하게 된다. 따라서 본 연구는 도덕성 및 인지 발달에서 매우 중요한 시기를 지나고 있는 청소년들을 대상으로 도덕적 인지 영역에서의 왜곡인 도덕적 이탈의 발달 을 설명하는 메커니즘을 확인했다는 점에서 의의가 있다. 둘 째, 부모의 심리적 특성 및 양육 행동이 청소년의 도덕적 이탈 에 미치는 영향에 관하여 모녀 관계의 역동에 초점을 두고 이 를 살펴본 연구는 다소 제한적이었다. 본 연구에서는 어머니 의 완벽주의가 심리적 통제를 통해 여자 청소년의 도덕적 이 탈에 미치는 영향을 검증하였다는 데 의의가 있다. 셋째, 도덕 적 이탈의 선행변인으로 부모의 심리적 통제를 살펴본 선행연 구들은 있었으나, 자녀의 도덕적 이탈을 불러일으키는 부모의 심리적 통제의 내면적 배경을 탐색한 연구는 비교적 드물었 다. 이에 본 연구는 어머니의 완벽주의가 심리적 통제를 통하 여 여자 청소년의 도덕적 이탈에 미치는 간접적인 영향을 검 증하였다는 데 의의가 있다. 이는 어머니의 자녀에 대한 완벽
주의가 자녀의 기능적인 발달 및 높은 성취에 대한 소망에서 오는 것임에도, 어머니의 지나친 기대가 오히려 청소년에게 부정적 정서를 유발하고 인지 발달에도 해로운 영향을 미치게 되어, 도덕적 이탈이라는 부적응적인 발달을 초래하는 결과를 보여준다. 본 연구는 청소년의 기능적인 도덕성 발달에 대한 부모의 심리적 상태 및 양육 행동의 중요성을 확인하였으며, 이와 같은 결과는 부모교육 프로그램의 기초자료로 활용될 수 있다는 점에서 이론적 함의를 지닌다.

\section{Notes}

This article is a part of the first author's master's thesis submitted in 2018. And this article was presented at the 2018 Annual Autumn Conference of the Korean Association of Child Studies.

\section{Conflict of interest statement}

No potential conflict of interest relevant to this article was reported.

\section{References}

\section{In English}

Almeida, A., Correia, I., \& Marinho, S. (2009). Moral disengagement, normative beliefs of peer group, and attitudes regarding roles in bullying. Journal of School Violence, 9(1), 23-36. doi:10.1080/15388220903185639

Bandura, A., Barbaranelli, C., Caprara, G. V., \& Pastorelli, C. (1996). Mechanisms of moral disengagement in the exercise of moral agency. Journal of Personality and Social Psychology, 71(2), 364-374. doi:10.1037/0022-3514.71.2.364

Bao, Z., Zhang, W., Lai, X., Sun, W., \& Wang, Y. (2015). Parental attachment and chinese adolescents' delinquency: The mediating role of moral disengagement. Journal of Adolescence, 44, 37-47. doi:10.1016/j.adolescence.2015.06.002

Barber, B. K. (1996). Parental psychological control: Revisiting a neglected construct. Child Development, 67(6), 3296-3319. doi:10.1111/j.1467-8624.1996.tb01915.x

Barber, B. K., \& Harmon, E. L. (2002). Violating the self: Parental psychological control of children and adolescents. In B. K. Barber (Ed.), Intrusive parenting: How psychological control affects children and adolescents (pp. 15-52). 
Washington, DC: American Psychological Association. doi: $10.1037 / 10422-002$

Belsky, J. (1984). The determinants of parenting: A process model. Child Development, 55(1), 83-96. doi:10.2307/1129836

Bronfenbrenner, U. (1979). Contexts of child rearing: Problems and prospects. American Psychologist, 34(10), 844-850. doi:10.1037/0003-066X.34.10.844

Deci, E. L., \& Ryan, R. M. (1987). The support of autonomy and the control of behavior. Journal of Personality and Social Psychology, 53(6), 1024-1037.

El-Sheikh, M., Hinnant, B., Kelly, R. J., \& Erath, S. (2010). Maternal psychological control and child internalizing symptoms: Vulnerability and protective factors across bioregulatory and ecological domains. The Journal of Child Psychology and Psychiatry, 51(2), 188-198. doi:10.1111/ j.1469-7610.2009.02140.x

Fontaine, R. G., Fida, R., Paciello, M., Tisak, M. S., \& Caprara, G. V. (2014). The mediating role of moral disengagement in the developmental course from peer rejection in adolescence to crime in early adulthood. Psychology, Crime \& Law, 20(1), 1-19. doi:10.1080/1068316X.2012.719622

Frost, R. O., Marten, P., Lahart, C., \& Rosenblate, R. (1990). The dimensions of perfectionism. Cognitive Therapy and Research, 14(5), 449-468. doi:10.1007/BF01172967

Hewitt, P. L., \& Flett, G. L. (1990). Perfectionism and depression: A multidimensional analysis. Journal of Social Behavior and Personality, 5(5), 423-437.

Hyde, L. W., Shaw, D. S., \& Moilanen, K. L. (2010). Developmental precursors of moral disengagement and the role of moral disengagement in the development of antisocial behavior. Journal of Abnormal Child Psychology, 38(2), 197-209. doi:10.1007/s10802-009-9358-5

Hymel, S., \& Bonanno, R. A. (2014). Moral disengagement processes in bullying. Theory Into Practice, 53(4), 278-285. doi:10.1080/00405841.2014.947219

Kishton, J. M., \& Widaman, K. F. (1994). Unidimensional versus domain representative parceling of questionnaire items: An empirical example. Educational and Psychological Measurement, 54(3), 757-765. doi:10.1177/0013164494054003022

Kline, R. B. (2010). Principles and practice of structural equation modeling (3rd ed.). New York: Guilford Publications.

Little, T. D., Cunningham, W. A., Shahar, G., \& Widaman, K. F. (2002). To parcel or not to parcel: Exploring the question, weighing the merits. Structural Equation Modeling: A Multidisciplinary Journal, 9(2), 151-173. doi:10.1207/ S15328007SEM0902_1

Menesini, E., Sanchez, V., Fonzi, A., Ortega, R., Costabile, A., \& Lo Feudo, G. (2003). Moral emotions and bullying: A cross-national comparison of differences between bullies, victims and outsiders. Aggressive Behavior, 29(6), 515-530. doi:10.1002/ab.10060

Slaney, R. B., \& Ashby, J. S. (1996). Perfectionists: Study of a criterion group. Journal of Counseling \& Development, 74, 393-398. doi:10.1002/j.1556-6676.1996.tb01885.x

Soenens, B., Elliot, A., Goossens, L., Vansteenkiste, M., Luyten, P., \& Duriez, B. (2013). The intergenerational transmission of perfectionism: Parents' psychological control as intervening variable. Journal of Family Psychology, 19(3), 358-366. doi:10.1037/0893-3200.19.3.358

Soenens, B., \& Vansteenkiste, M. (2010). A theoretical upgrade of the concept of parental psychological control: Proposing new insights on the basis of self-determination theory. Developmental Review, 30(1), 74-99. doi:10.1016/ j.dr.2009.11.001

Soenens, B., Vansteenkiste, M., Duriez, B., \& Goossens, L. (2006). In search of the source of psychologically controlling parenting: The role of parental separation anxiety and parental maladaptive perfectionism. Journal of Research on Adolescence, 16(4), 539-559. doi:10.1111/j.1532-7795.2006.00507.x

Soenens, B., Vansteenkiste, M., Luyten, P., Duriez, B., \& Goossens, L. (2005). Maladaptive perfectionistic self-representations: The mediational link between psychological control and adjustment. Personality and Individual Differences, 38(2), 487-498. doi:10.1016/j.paid.2004.05.008

Stoeber, J., \& Yang, H. (2016). Moral perfectionism and moral values, virtues, and judgements: Further investigations. Personality and Individual Differences, 88, 6-11. doi:10.1016/ j.paid.2015.08.031

Trentacosta, C. J., Criss, M. M., Shaw, D. S., Lacourse, E., Hyde, L. W., \& Dishion, T. J. (2011). Antecedents and outcomes of joint trajectories of mother-son conflict and warmth during middle childhood and adolescence. Child development, 82(5), 1676-1690. doi:10.1111/j.1467-8624.2011.01626.x

Wang, X., Yang, L., Gao, L., Yang, J., Lei, L., \& Wang, C. (2017). Childhood maltreatment and Chinese adolescents' bullying and defending: The mediating role of moral disengagement. Child Abuse \& Neglect, 69, 134-144. doi:10.1016/ j.chiabu.2017.04.016

\section{In Korean}

Cho, I.-H. (2012). The relationship between intrusive child-rearing attitude of the parents and morality of students as perceived by male high-school students. The Educational Research for Tomorrow, 25(1), 95-130.

Choi, M. J. (2010). The influence of psychological control on well-being: Mediating effect of conflictual independence (Master's thesis). Retrieved from http://www.riss.kr/ link?id=T11968266

Chon, M.-S., \& Sohn, E. (2013). The influence of maternal 
psychological control on adolescents' aggression - The moderating effects of adolescents' self-control and maladaptive emotion regulation -. Youth Facility and Environment, 11(2), 19-27.

Hong, S. H. (2000). The criteria for selecting appropriate fit indices in structural equation modeling and their rationales. Korean Journal of Clinical Psychology, 19(1), 161-177.

Hwang, S., Kim, D., \& Kim, H. (2015). A national survey of youth risk behaviors-The first year (Question development)-. Retrieved from Korea Youth Counseling \& Welfare Institute website: https://www.kyci.or.kr

Im, K.-E., \& Chun, Y.-J. (2009). Intergenerational transmission of mother-daughter attachment and unmarried adult daughter's ego-resiliency. Journal of Korean Home Management Association, 27(1), 197-208.

Jang, E. S. (2011). The effects of the mother's perfectionism about their children perceived by children on social anxiety: Mediating effects of self-acceptance (Master's thesis). Retrieved from http://www.riss.kr/link?id=T12543575

Kim, G. (2010). AMOS 18.0 gujobangjeongsik mohyeong bunseok [AMOS 18.0 구조방정식 모형 분석]. Seoul: Hannarae Academy.

Kim, H.-Y., \& Park, S.-Y. (2008). The effects of mothers' perfectionism and psychological control behavior on children's perfectionism and children's depression. The Korean Journal of Developmental Psychology, 21(3), 115-131.

Kim, J. M., \& Kim, J. M. (2013). The effect of parental psychological control and moral disengagement on children's participant role behavior in a bullying situations. Korean Journal of Child Studies, 34(6), 13-29. doi:10.5723/ KJCS.2013.34.6.13

Kim, S. (2005). A study of the relationships between perfectionism tendency, depression, and self-esteem of the undergraduate students-Focused on the APS-R (the almost perfectionism scales-revised)(Master's thesis). Retrieved from http://www. riss.kr/link?id=T10003931

Lee, H. S. (2016). Influence of parental psychological control on adolescents' internalizing and externalizing problematic behaviors: The moderating effect of moral disengagement (Master's thesis). Retrieved from http://www.riss.kr/ link?id=T14185212

Nam, S., \& Han, S. (2002). The family differentiation level, quality of family relationship, and intimacy. Korean Journal of Psychological and Social Issues, 8(2), 33-49.

Park, Y., Kim, U., \& Tak, S. (2011). Influence of parents, friends, moral disengagement and relational efficacy on cyber delinquency. The Korean Journal of Educational Psychology, 25(3), 617-645.

Seo, M. J. (2013). The influences of moral disengagement and moral emotions on bullying assistant behavior. Korean Journal of Child Studies, 34(6), 123-138. doi:10.5723/ KJCS.2013.34.6.123

Seo, M. J., \& Kim, K. Y. (2006). Analysis of variables for classifying types of outsiders in bullying situations. Korean Journal of Child Studies, 27(6), 35-51.

Wang, H. K., \& Han, S. Y. (2013). Effects of mother's neuroticism, perfectionism and psychological control on young children's internalizing problem behavior. Journal of Human Ecology, $17(1), 41-53$.

Yun, N. (2017). The effects of paternal and maternal parenting behaviors on adolescents' delinquency: The mediating role of moral disengagement (Master's thesis). Retrieved from http://www.riss.kr/link?id=T14717887

\section{ORCID}

Eun-Hye Sohn https://orcid.org/0000-0002-0129-9636

Sae-Young Han https://orcid.org/0000-0001-8207-5927

Received February 28, 2019 Revision received March 27, 2019

Accepted April 12, 2019 